\title{
Improvement of nasal breathing and patient satisfaction by the endonasal dilator Airmax ${ }^{\circledR *}$
}

\author{
Peter W. Hellings $s^{1,2}$ and Gilbert J. Nolst Trenité ${ }^{3}$ \\ ' Department of Otorhinolaryngology, Head and Neck surgery, University Hospitals Leuven, Leuven, Belgium \\ 2Department of Otorhinolaryngology, Academic Medical Centre Amsterdam, Amsterdam, the Netherlands \\ ${ }^{3}$ Department of Otorhinolaryngology, Head and Neck surgery, University Hospital Ghent, Belgium
}

Rhinology 52: 31-34, 2013

DOI:10.4193/Rhino13.061

*Received for publication:

May 19, 2013

Accepted: July 8, 2013

\begin{abstract}
Background: Patients suffering from nasal obstruction due to external nasal valve dysfunction may benefit from either corrective surgery or a conservative approach with a nasal dilator. At present, devices for widening the external nasal valve region can be applied externally or endonasally. It remains unknown to what extent the endonasal dilator Airmax ${ }^{\circledR}$ objectively improves the nasal flow and can be offered as an alternative for surgery.
\end{abstract}

Methodology: Thirty patients suffering from nasal obstruction due to external nasal valve problems were proposed to use the nasal dilator for 4 weeks as an alternative for corrective surgery. The improvement of nasal flow by the dilator was evaluated by measuring the peak nasal inspiratory flow (PNIF). Then, patients were asked for their willingness to continue to use the nasal dilator or to undergo nasal valve surgery.

Results: The endonasal dilator improved the mean PNIF from baseline values with a mean increase of $176.1 \%$. After a 4 week trial period, 19 of 30 patients expressed the intention to continue the use of the nasal dilator. Inappropriate size, local irritation and/or aesthetic nasal complaints were mentioned by the other patients as reasons for discontinuation of using the nasal dilator.

Conclusion: The endonasal dilator Airmax ${ }^{\circledast}$ represents a powerful device to improve nasal breathing in the target patients and therefore represents a good alternative for corrective surgery.

Key words: nasal obstruction, nasal flow, nasal dilator, Airmax ${ }^{\circledast}$

\section{Introduction}

Patients with nasal obstruction may have a variety of mucosal and/or anatomical abnormalities being responsible for their impaired nasal breathing. The distinction between mucosal and anatomical abnormalities is made on the base of a proper clinical examination ${ }^{(1)}$. Among the non-mucosal etiologies of nasal obstruction, nasal septal deviation, septal perforations and/or valve dysfunction are the most frequently encountered conditions. In patients with nasal obstruction, external valve problems are often overlooked in spite of the ease of clinical examination.
Inadequate function of the outer valve with either alar collapse at the time of nasal inspiration and/or narrow nostrils may become obvious by performing the Cottle test ${ }^{(2)}$. The latter test involves the evaluation of the subjective improvement in nasal breathing by widening the external valve area via either manual distraction of the cheek in lateral direction or by lateral displacement of the lateral crurae by non-traumatic instruments.

The management of nasal obstruction depends on the underlaying etiology. In case of external valve problems with positive 
Cottle test, surgery is often advocated involving a single or combined surgical technique(s) to optimize the size and function of the nasal valve. Lateral crural reinforcement by placement of alar batten grafts ${ }^{(3)}$, or lateral crural pull up techniques ${ }^{(4,5)}$ have been reported to improve the nasal breathing. Of note, the functional restoration of the nasal valve region may involve broadening of the alar vault region of the nose ${ }^{(6)}$. Therefore, aesthetical considerations have to be taken into account at the time of scheduling a surgical intervention, as patients need to be fully aware of the consequences of the surgery.

In those patients where surgery is not primarily indicated or desired by the patient, non-surgical options should be discussed. Several devices for external or endonasal widening of the valve area have been designed for use by sportsmen, snorers and/ or patients with nasal breathing problems. So far, we lack good data on the objective improvement of nasal breathing by these devices. A recent study using the endonasal dilater Nasanita ${ }^{\circledR}$ (Siemens, Germany) in 10 patients with external valve problems demonstrated beneficial effects on alar collapse and active anterior rhinomanometry data ${ }^{(7)}$. Other devices like Nozovent ${ }^{\circledR}$ and Breath Right ${ }^{\circledast}(8)$ are mechanical dilators with only empiric experience on efficacy and indications. Of note, we have no clue what percentage of patients may benefit from these devices and ultimately decline the proposal of surgery as they are satisfied with the device. As a result of the clinical need to objectively evaluate the improvement of nasal breathing by the endonasal dilator Airmax ${ }^{\circledast}$ and the clinical need to predict success rates of the application of the device by the patients, this study was designed.

\section{Materials and methods}

Patients population

Patients with invalidating bilateral nasal obstruction due to external nasal valve dysfunction were selected for participation in this prospective study running from March 2011 until March 2012 in the Rhinology clinic of the Department of Otorhinolaryngology of the University of Leuven, Belgium. Of the patients with external nasal valve dysfunction, only those with bilateral alar collapse and/or narrow nostrils were selected for participation in the trial. All patients had a positive Cottle test, i.e. the improvement of nasal breathing by lateral distraction of the cheek and/or by lateral displacement of the nasal alar region. The absence of significant mucosal disease and/or rhinosinusitis was assured by nasal endoscopy. Normal active anterior rhinomanometry as well as a normal anterior acoustic rhinometry were inclusion criteria for this study.

A general medical and surgical history was taken, specifically focusing on nasal medication and previous nasal surgery. The study was approved by the local Medical Ethical Committee of the University Hospitals of Leuven.
Endonasal dilator and peak nasal inspiratory flow (PNIF) measurement

At the outpatient clinic, patients were instructed how to apply the Airmax ${ }^{\circledR}$ nasal dilator (Figure 1) and were helped with the application of the dilator for the first time. Either a small size or medium size dilator was inserted based on the evaluation of the medical doctor (PWH). If the device turned out not to have the proper size, the larger or smaller dilator was applied and instructed to use for $4 \mathrm{w}$.

The peak nasal inspiratory flow (PNIF) was measured, at the outpatient clinic before and after application of the dilator, to evaluate the objective improvement of nasal patency and inspiratory flow. Before and after Airmax ${ }^{\circledR}$ insertion, several consecutive measurements had been made and the highest value of 3 consecutive measurements with less than $10 \%$ variability was chosen for the records, as described previously ${ }^{(1)}$. Patients were donated one of the commercially available Airmax ${ }^{\circledast}$ kits with 2 dilators for free, and instructed to apply the device as needed during sleep, during sports and/or during daytime activities.

Evaluation of subjective satisfaction of the endonasal dilator

At $4 \mathrm{w}$ after the initial consultation, patients were reevaluated at the outpatient Rhinology clinic. Patients were asked for their willingness to continue to use the device or their preference to undergo surgery to improve the nasal breathing. In those expressing the desire to stop using the nasal dilator, the major reason underlying the decision was asked and noted.

\section{Data analyses and statistics}

Statistical analysis was performed using the non-parametric, paired $t$-test with a value of $p<0.05$ being statistically significant. Data are presented as means \pm standard errors of the mean (SEM).

\section{Results}

\section{Patient characteristics}

Thirty patients with nasal obstruction primarily caused by nasal valve dysfunction and with a positive Cottle test were included in this study. The mean age of the study population was 50.4 \pm 14.3 years of age, with 20 male patients (66\%). Eleven of 30 patients had undergone nose surgery in the past (septal correction, turbinate reduction and/or rhinoplasty) whereas the remaining 19 had never undergone a nasal intervention. None of the patients was on current nasal anti-inflammatory treatment.

Improvement of PNIF by the endonasal dilator Mean baseline PNIF values were $84.8 \pm 20.1 \mathrm{l} / \mathrm{min}$, with improvement by the dilator in all patients to a mean of $142.5 \pm 34.8 \mathrm{l} /$ $\min (p<0.005)$. The mean percentage of individual increase in 


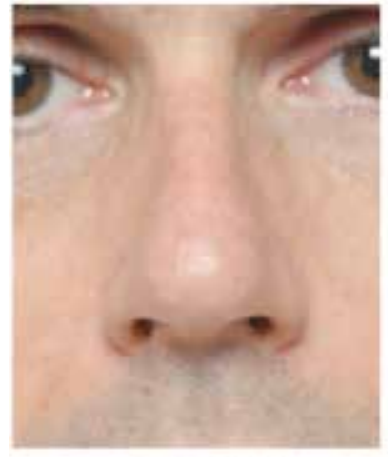

WITHOUT dilator

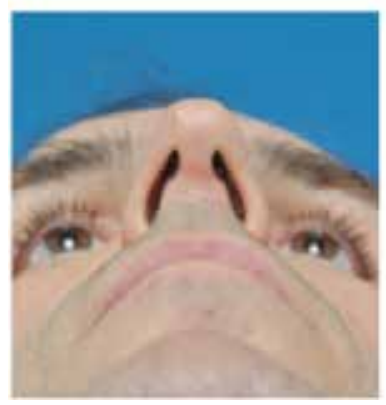

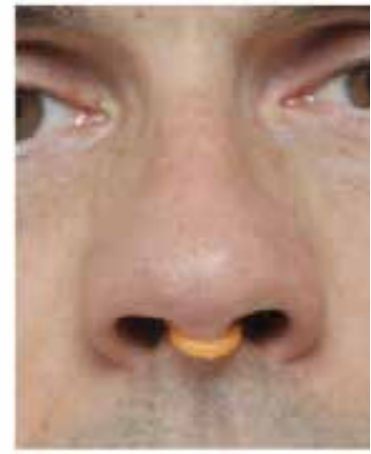

WITH dilator

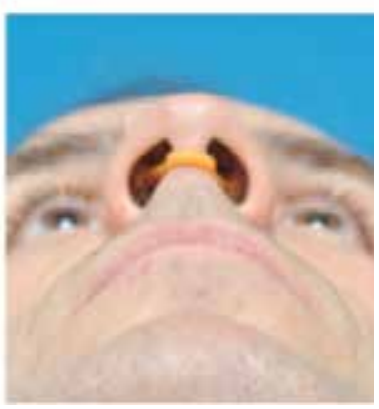

Figure 1. Frontal (upper panel) and inferior (lower panel) views on the nose with (righ panel) and without (left panel) the nasal dilator, showing an increase in nasal diameter at the level of the external nasal valve area.

PNIF values by Airmax ${ }^{\circledR}$ was $176.1 \pm 59.6 \%$.

No differences in absolute PNIF values were found between male and female patients at baseline $(82.7 \pm 18.6$ and $89.0 \pm 7.3$ $\mathrm{I} / \mathrm{min}$, respectively), nor after the application of the device (143.3 \pm 7.7 and $138.2 \pm 10.8 \mathrm{l} / \mathrm{min}$, respectively). Similarly, no differences were observed in PNIF values between patients younger and older than 50 years of age, or between previously operated and non-operated patients (data not shown).

\section{Patients' preference for continuation of the endonasal} dilator

Of the 30 patients with subjective improvement of nasal breathing by the Airmax ${ }^{\circledast}$ device at baseline visit, 19 out of 30 patients (63.3\%) expressed the preference to further use the device after the $4 \mathrm{w}$ trial period. In the latter group, the mean baseline increase in PNIF values $(85.2 \pm 34.8 \mathrm{l} / \mathrm{min}$ ) was not different from the group that did not want to continue using the device $(84.1 \pm 4.3 \mathrm{l} / \mathrm{min}, \mathrm{n}=11)$. There was also no difference in mean percentages of increase in PNIF values by the Airmax ${ }^{\circledR}$ device at baseline between those being satisfied and those not satisfied with the device $(189.2 \pm 68.7$ and $153.5 \pm 9.2 \mathrm{l} / \mathrm{min}$, respectively, $p>0.05$ ).

Amongst those patients who expressed the desire not to continue wearing the Airmax ${ }^{\circledR}$ device after the $4 \mathrm{w}$ of trial period, the following main reasons for discontinuation were mentioned:
3/11 mentioned inappropriate size with loss of device during sleep or exercise as bothersome factor, $2 / 11$ reported local irritation in the nasal cavity by the device, $2 / 11$ expressed a desire for aesthetic nasal correction at the time of functional improvement, and the remaining 4/11 wanted a definite solution for their nasal obstruction problem by surgery rather than a nonsurgical, temporary solution.

\section{Discussion}

We here demonstrate the beneficial effects of the Airmax ${ }^{\circledast}$ endonasal dilator in a real-life clinical setting. All patients with external valve dysfunction showed major benefit from the dilator, as evaluated by the absolute and relative increase in PNIF in all patients. After the $4 \mathrm{w}$ trial period, 19 of 30 patients were satisfied with the Airmax ${ }^{\circledast}$ nasal dilator, expressing the preference to continue wearing the device.

This study raises several interesting issues regarding the therapeutic approach of nasal valve dysfunction. Firstly, this study offers the first step in evaluating the success of the endonasal dilator as an alternative for surgery. At present, patients with nasal valve dysfunction are being proposed to undergo either corrective valve surgery or a conservative approach using nasal dilators, without surgeons being able to give an estimated success rate of the conservative approach. Both external (Breath Right $^{\oplus}$ ) and as well as endonasal (Nozovent ${ }^{\oplus}$ or Airmax ${ }^{\circledR}$ ) dilators have been reported to be helpful in snorers, sportsmen and patients with nasal obstruction, without data on subjective evaluation by the patient ${ }^{(9-12)}$. Here, we show that 19 out of 30 selected patients with external valve problems being the reason for nasal obstruction intended to continue to use the dilator Airmax ${ }^{\circledR}$. This argument can be used in every day clinic to explain the patients the subjective benefit of the Airmax ${ }^{\circledR}$ dilator.

Until recently, we only had limited objective data on the improvement of nasal breathing by nasal dilators ${ }^{(9-12)}$. The reported improvement of nasal flow by the dilators was performed by either acustic rhinometry ${ }^{(9,10)}$ or rhinomanometry ${ }^{(11,12)}$. Regarding the different techniques for measuring nasal flow, a European consensus group recently stated that PNIF measurements are superior to other means of evaluation of nasal flow due to the fact that PNIF data correlate with the subjective feeling of nasal obstruction and that the nasal flow is measured without distortion of the nasal valve area by a nozzle ${ }^{(2)}$. Therefore, PNIF measurements had been chosen for evaluation of nasal flow in this study.

Of note, it was interesting to observe that almost $2 / 3$ of patients expressed the desire to continue to use the nasal dilator Airmax ${ }^{\circledast}$. We are well aware of the fact that this high degree of patient satisfaction with this endonasal dilator does reflect a combination of factors like subjective improvement of nasal 
breathing, the ease of wearing the device, the lack of social inhibition by an endonasal rather than external device, and/or the fear for surgery. In the remaining $1 / 3$, the use of the nasal dilator was discontinued on the base of several reasons that are device-related, like local irritation and inappropriate size. Other reasons like the choice for a more definitive solution and/ or the combined functional-aesthetic improvement of the nose by the surgery can be considered as device-unrelated. Interestingly enough, none of the patients reported aesthetic or social impairment by wearing the device.

In conclusion, we here present the first data on subjective improvement of nasal flow and satisfaction in patients with nasal valve dysfunction and obstruction using the nasal dilator Airmax ${ }^{\circledast}$. Further studies in this field are warranted to compare the different nasal dilators and/or compare the success rate of conservative vs surgical solutions for nasal valve dysfunction.

\section{Authorship contribution}

This was an academic study performed by the key investigator (PWH) and with scientific help of the co-author (GJNT).

\section{Conflict of interest}

The authors state they have no major conflict of interest in relation to this study that was carried out without financial support of the Airmax B.V. company, The Netherlands. The devices delivered to the patients were offered by the company, without further interference in the elaboration and/or planning of the experiments.

\section{References}

1. Hellings PW, Scadding G, Alobid I, Bachert C, Fokkens WJ, Gerth van Wijk R, et al. Executive summary of European Task Force document on diagnostic tools in rhinology. Rhinology. 2012; 50: 339-352.

2. Scadding G, Hellings P, Alobid I, Bachert C, Fokkens W, van Wijk RG, et al. Diagnostic tools in Rhinology EAACI position paper. Clin Transl Allergy. 2011; 1: 2.

3. Andre RF, D'Souza AR, Kunst HP, Vuyk HD. Sub-alar batten grafts as treatment for nasa valve incompetence; description of technique and functional evaluation. Rhinology. 2006; 44: 118-122.

4. Menger DJ. Lateral crus pull-up: a method for collapse of the external nasal valve. Arch Facial Plast Surg. 2006; 8: 333-337

5. Andre RF, Vuyk HD. Nasal valve surgery; our experience with the valve suspension technique. Rhinology. 2008; 46: 66-69.

6. Ingels KJ, Orhan KS, van Heerbeek N. The effect of spreader grafts on nasal dorsal width in patients with nasal valve insufficiency. Arch Facial Plast Surg. 2008; 10 354-356.

7. Riechelmann $H$, Karow E, DiDio D, Kral F. External nasal valve collapse - a case-control and interventional study employing a novel internal nasal dilator (Nasanita). Rhinology. 2010; 48: 183-188.

8. Ellegard E. Mechanical nasal alar dilators Rhinology. 2006; 44: 239-248.

9. Griffin JW, Hunter G, Ferguson D, Sillers MJ Physiologic effects of an external nasal dilator. Laryngoscope. 1997; 107: 1235-1238.

10. Ho WK, Wei WI, Yuen AP, Hui Y. Effect of the external nasal dilator on nasal minimal cross-sectional area in orientals as assessed by acoustic rhinometry. J Otolaryngol. 2000; 29: 367-370.

11. Hoijer U, Ejnell $H$, Hedner J, Petruson B, Eng $L B$. The effects of nasal dilation on snoring and obstructive sleep apnea. Arch Otolaryngol Head Neck Surg. 1992; 118: 281-284.
12. Kirkness JP, Wheatley JR, Amis TC. Nasal airflow dynamics: mechanisms and responses associated with an external nasal dilator strip. Eur Respir J. 2000; 15: 929-936.

Peter W. Hellings, MD, PhD

Department of Otorhinolaryngology

Head and Neck Surgery

University Hospitals Leuven

Kapucijnenvoer 33

3000 Leuven

Belgium

Tel: $+32-16-332338$

Fax: +32-16-34 6035

E-mail: peter.hellings@uzleuven.be 